\title{
Article \\ Broadband-Printed Traveling-Wave Tube Based on a Staggered Rings Microstrip Line Slow-Wave Structure
}

\author{
Ruichao Yang ${ }^{1}\left(\mathbb{D}\right.$, Lingna Yue ${ }^{1, *} \mathbb{D}$, Jin $X u^{1, *}$, Pengcheng Yin ${ }^{1} \mathbb{1}$, Jinjing Luo ${ }^{1}$, Hexin Wang ${ }^{1}\left(\mathbb{D}\right.$, Dongdong Jia ${ }^{1}$, \\ Jian Zhang ${ }^{1}$, Hairong Yin ${ }^{1}$, Jinchi Cai ${ }^{1}{ }^{1}$, Guo Guo ${ }^{1}$, Guoqing Zhao ${ }^{1}$, Wenxiang Wang ${ }^{1}$, Dazhi Li ${ }^{2}$ and \\ Yanyu Wei ${ }^{1}$
}

check for updates

Citation: Yang, R.; Yue, L.; Xu, J.; Yin, P.; Luo, J.; Wang, H.; Jia, D.; Zhang, J.; Yin, H.; Cai, J.; et al.

Broadband-Printed Traveling-Wave

Tube Based on a Staggered Rings

Microstrip Line Slow-Wave Structure. Electronics 2022, 11, 384. https:// doi.org/10.3390/electronics11030384

Academic Editor: Geok Ing Ng

Received: 31 December 2021

Accepted: 19 January 2022

Published: 27 January 2022

Publisher's Note: MDPI stays neutral with regard to jurisdictional claims in published maps and institutional affiliations.

Copyright: (C) 2022 by the authors. Licensee MDPI, Basel, Switzerland. This article is an open access article distributed under the terms and conditions of the Creative Commons Attribution (CC BY) license (https:// creativecommons.org/licenses/by/ $4.0 /)$.
1 National Key Laboratory of Science and Technology on Vacuum Electronics, University of Electronic Science and Technology of China, Chengdu 611731, China; ruichaoyang@foxmail.com (R.Y.); yyppcchh@163.com (P.Y.); jinjingluo_uestc@163.com (J.L.); whx427@126.com (H.W.); DongdJia@outlook.com (D.J.); jiann.zhang@outlook.com (J.Z.); hryin@uestc.edu.cn (H.Y.); jccai@uestc.edu.cn (J.C.); guoguo@uestc.edu.cn (G.G.); zhaogq@uestc.edu.cn (G.Z.); wxwang@uestc.edu.cn (W.W.); yywei@uestc.edu.cn (Y.W.)

2 Neubrex Company Limited, Kobe 6500023, Japan; dazhi_li@hotmail.com

* Correspondence: Inyue@uestc.edu.cn (L.Y.); alionxj@uestc.edu.cn (J.X.)

\begin{abstract}
To increase the output power of microstrip line traveling-wave tubes, a staggered rings microstrip line (SRML) slow-wave structure (SWS) based on a U-shaped mender line (U-shaped ML) SWS and a ring-shaped microstrip line (RML) SWS has been proposed in this paper. Compared with U-shaped ML SWS and RML SWS, SRML SWS has a wider transverse width, which means SRML SWS has a larger area for beam-wave interaction. The simulation results show that SRML SWS has a wider bandwidth than U-shaped ML SWS and a lower phase velocity than RML SWS. Input/output couplers, which consist of microstrip probes and transition sections, have been designed to transmit signals from a rectangular waveguide to the SWS; the simulation results present that the designed input/output structure has good transmission characteristics. Particle-in-cell (PIC) simulation results indicate that the SRML TWT has a maximum output of $322 \mathrm{~W}$ at $32.5 \mathrm{GHz}$ under a beam voltage of $9.7 \mathrm{kV}$ and a beam current of $380 \mathrm{~mA}$, and the corresponding electronic efficiency is around $8.74 \%$. The output power is over $100 \mathrm{~W}$ in the frequency range of $27 \mathrm{GHz}$ to $38 \mathrm{GHz}$.
\end{abstract}

Keywords: microstrip line; slow-wave structure (SWS); traveling-wave tube (TWT); Ka-band

\section{Introduction}

High average power at millimeter-wave frequency, which is lightweight, low voltage, compact, and broadband, is demanded in many significant applications such as electronic counter measures, radar, and communications [1]. Solid-state amplifiers are lightweight and compact, but the output power, bandwidth, and efficiency struggle to meet the requirements. Traveling-wave tubes (TWTs) such as helix TWT [2], coupled-cavity TWT (CC-TWT) [3], and folded-waveguide TWT (FW-TWT) [4] show great potential in this frequency range due to high-power output or broadband. However, the conventional traveling-wave tubes are heavy, high voltage, or hard to fabricate at millimeter-wave frequency.

Planar TWT has become an attractive interaction structure because it is lightweight, compact, and can be mass fabricated. Numerous investigations have been conducted on meander-line slow-wave structure (ML-SWS) [5-9] and its deformed structure [10-18] in recent years. As planar SWS is a 2D structure, the fabrication problem that conventional SWS such as helix, coupled-cavity, and folded-waveguide met when the operating frequency was Ka-band or above can be solved using micro-electromechanical systems (MEMS).

The conventional microstrip line SWSs have the advantage of miniaturization and low voltage, but these are also their flaws. This feature of miniaturization leads to the small electron beam current used by the microstrip TWT, which causes the output power of the 
microstrip TWT to be relatively low. As the force exerted by the high-frequency field on the sheet electron beam in the microstrip TWT is not symmetrical, and the beam voltage of the microstrip TWT is usually very low, focusing the sheet electron beam was a huge challenge.

To obtain a higher output power, a staggered rings microstrip line slow-wave structure (SRML SWS) based on a ring-shaped microstrip line slow-wave structure [18] (RML SWS) has been designed. By staggered placement of adjacent rings, the area for beam-wave interaction was increased, which resulted in an increased beam current with the same current density.

The content of this paper is arranged as follow. Firstly, the dispersion characteristics of SRML SWS are analyzed and discussed in Section 2. In Section 3, the transmission characteristics of SRML SWS with input/output couplers are presented. Section 4 shows the particle-in-cell (PIC) simulation results of the designed SRML TWT. Finally, the fabrication of SRML SWS and the results are discussed and concluded in Sections 5 and 6.

\section{Dispersion Characteristics of SRML SWS}

Figure $1 \mathrm{a}$ is the traditional U-shaped meander line slow-wave structure (ML SWS); by overlapping two U-shaped metal lines of the ML SWS with the opposite phases, a ringshaped microstrip line slow-wave structure (RML SWS) [18], as shown in Figure 1b, was obtained. Additionally, as shown in Figure 1c, a staggered rings microstrip line slow-wave structure (SRML SWS) was constructed through periodically interlacing adjacent rings of the RML SWS. The SWS consisted of dielectric substrate and the metal line placed on the surface of the substrate. The staggered distance of the two rings is $\delta$, the width of the ring is $w_{r}$, the period length is $p$, the inner gap of the ring is $s$, the width of the metal line is $w$, the thickness of the metal line is $t$, the width of the shielding box and substrate is $a$, the height of the shielding box is $h_{a}$, and the thickness of the dielectric substrate is $h_{d}$. The material of the dielectric substrate was quartz glass, and the metal line was copper made. The microstrip line SWS was placed in a metal-shielding cavity to maintain a vacuum state, and copper was the material used.

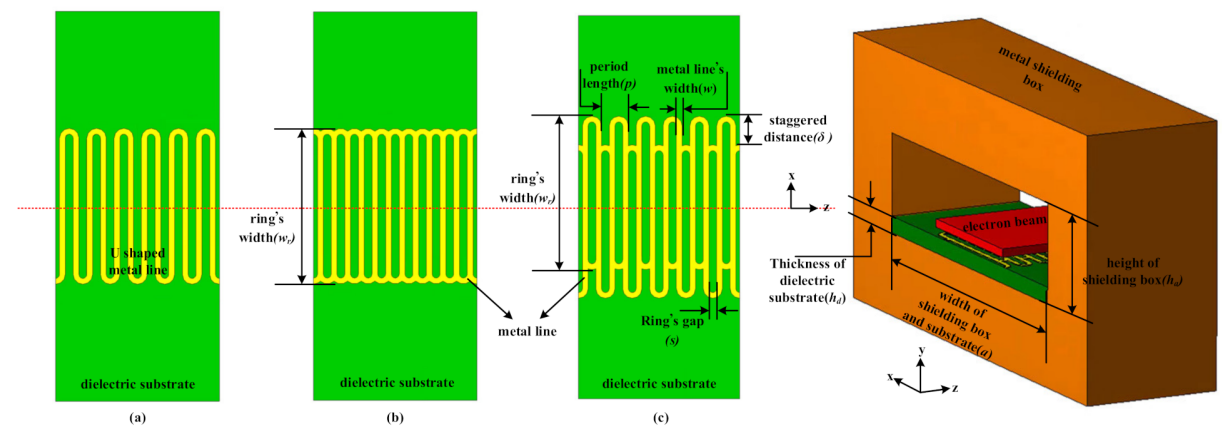

Figure 1. The diagram of (a) U-shaped ML SWS, (b) RML SWS, and (c) SRML SWS.

The phase velocity and interaction impedance are defined by the following:

$$
\begin{gathered}
v_{p}=\frac{\omega}{\beta_{n}} \\
K_{\mathrm{cn}}=\frac{\left|E_{z n}\right|^{2}}{2 \beta_{n}^{2} P_{\omega}} \\
\beta_{\mathrm{n}}=\beta_{0}+\frac{2 n \pi}{p} \quad n=0, \pm 1, \pm 2, \cdots
\end{gathered}
$$

Here, $\omega$ is the angular frequency, $P_{\omega}$ is the transmission power along the longitudinal direction, $E_{z n}$ is the amplitude of the longitudinal electrical field, $p$ is the period length of the SWS and $\beta_{0}$ is the phase constant of fundamental wave, which equals $\phi / p$, and $\phi$ is the 
phase shift in one period. By compiling and solving the above formulas in a field calculator of HFSS, the phase velocity and the interaction impedance of the SWS can be obtained.

Figure 2 presents the simulation results of the normalized phase velocity and the interaction impedance of the U-shaped ML SWS, RML SWS, and SRML SWS with the same ring width and period length. As shown in Figure 2a, the RML SWS and SRML SWS have larger bandwidths than that of the U-shaped ML SWS, but their phase velocity is far higher than that of the ML SWS. Additionally, by staggering the adjacent rings, the normalized phase velocity of the SRML SWS was significantly decreased when compared with the RML SWS. Additionally, the SRML SWS had a smaller change rate of normalized phase velocity, which means the SRML TWT had a wider working-frequency band. Figure $2 \mathrm{~b}$ is a comparison diagram of the interaction impedance of the three structures. The interaction impedance was calculated $0.1 \mathrm{~mm}$ away from the upper face of the metal line. Figure $2 \mathrm{~b}$ shows that the U-shaped ML SWS had a larger interaction impedance at the lower frequency band, but the interaction impedance of the SRML SWS and the RML SWS were larger at the Ka-band.

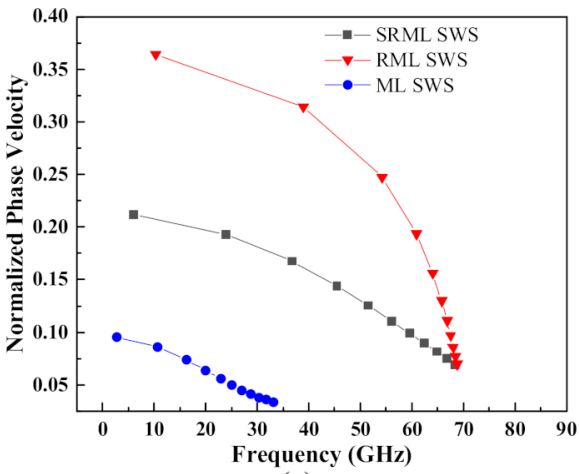

(a)

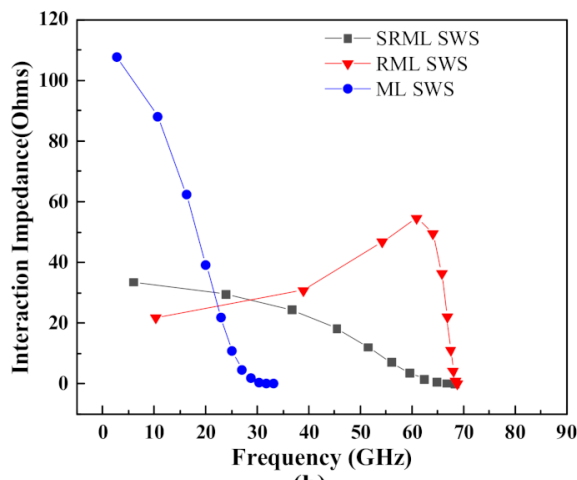

(b)

Figure 2. The comparisons between ML SWS, RML SWS, and SRML SWS. (a) Normalized phase velocity, (b) interaction impedance.

Additionally, Figure 3 shows that the interaction impedance varied with the position of the calculation line of coupling impedance at $32.5 \mathrm{GHz}$. It is obvious that the SRML SWS had a larger coupling area than the RML SWS, which means a wider electron beam can be used for the beam-wave interaction of SRML TWT. In other words, an SRML TWT can be driven by an electron beam with a higher beam current than that of an RML TWT at the same current density, and the SRML TWT would have a higher output power.

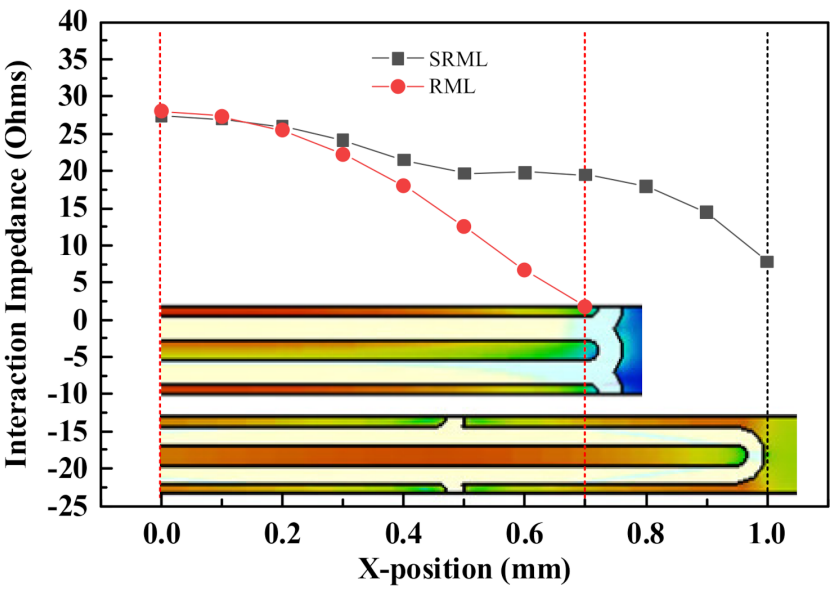

Figure 3. The variation of the interaction impedance with $x$ position of the interaction impedance calculation line. 
Figure 4 presents the curves of the normalized phase velocity and the interaction impedance with different values for the staggered distance of the rings. As the degree of interleaving of the rings increased, the normalized phase velocity and the coupling impedance decreased in the frequency band of $30 \mathrm{GHz}$ to $40 \mathrm{GHz}$. Figure 5 shows the influence of the ring width on the normalized phase velocity and the coupling impedance of the SRML SWS. As the $w_{r}$ increased, the normalized phase velocity and the bandwidth of the SRML SWS decreased. However, the interaction impedance slightly increased below the frequency of $40 \mathrm{GHz}$.

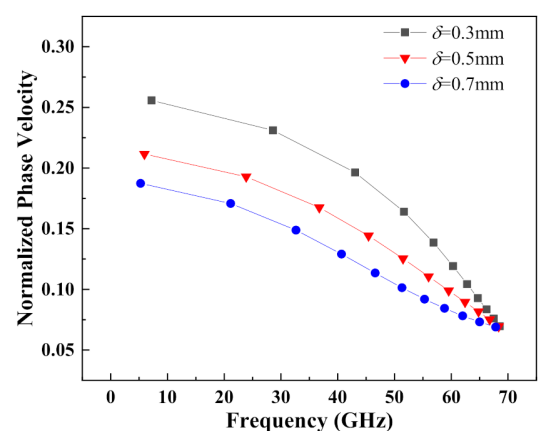

(a)

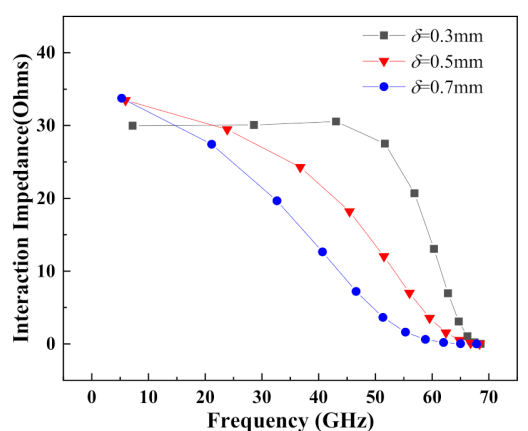

(b)

Figure 4. (a) Normalized phase velocity with different $\delta$, (b) interaction impedance with different $\delta$.

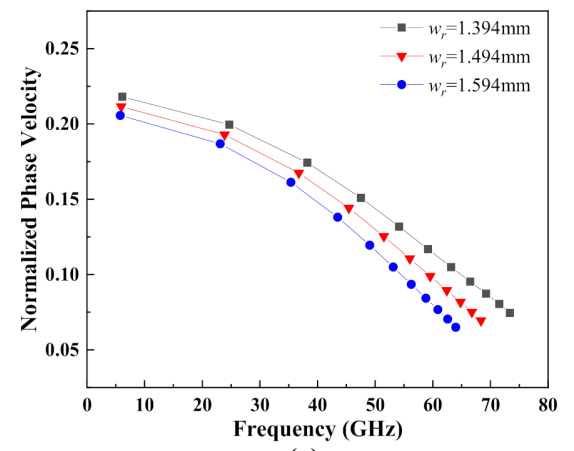

(a)

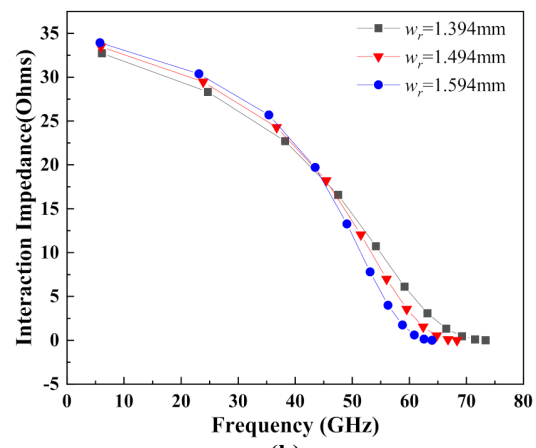

(b)

Figure 5. (a) Normalized phase velocity with different $w_{r},(\mathbf{b})$ interaction impedance with different $w_{r}$.

Figure 4 presents the curves of the normalized phase velocity and the interaction impedance with different values for the staggered distance of the rings. As the degree of interleaving of rings increased, the normalized phase velocity and the coupling impedance decreased in the frequency band of $30 \mathrm{GHz}$ to $40 \mathrm{GHz}$. Figure 5 shows the influence of the ring width on the normalized phase velocity and the coupling impedance of the SRML SWS. As the $w_{r}$ increased, the normalized phase velocity and the bandwidth of SRML SWS decreased. However, the interaction impedance slightly increased below the frequency of $40 \mathrm{GHz}$.

Through a series of simulation and optimizations, the value parameters of the SRML SWS were obtained, as shown in Table 1.

Table 1. The parameters of the SRML SWS.

\begin{tabular}{cc}
\hline Parameter & Value (mm) \\
\hline$p$ & 0.128 \\
$w_{r}$ & 1.494 \\
$w$ & 0.04 \\
$s$ & 0.034 \\
$\delta$ & 0.5 \\
$h_{d}$ & 0.254 \\
$t$ & 0.005 \\
$a$ & 4 \\
$h_{a}$ & 1.254 \\
\hline
\end{tabular}




\section{The Transmission Characteristics of the SRML SWS}

The model of SRML SWS used for the transmission characteristics simulation was established in CST Microwave Studio, as shown in Figure 6. The model consists of 100 periods of SRML SWSs, 6 periods of transition section, microstrip probes, rectangular waveguides, and a metal shielding box. Through the microstrip probes, the input signal was converted from the $\mathrm{TE}_{10}$ mode in the rectangular waveguide to the quasi-TEM mode in the microstrip line. The material of the shielding box was copper. In the simulation, the conductivity of the copper was set as $2.8 \times 10^{7} \mathrm{~S} / \mathrm{m}$, the relative permittivity of the quartz glass was 3.75 , and the loss tangent was $4 \times 10^{-4}$.

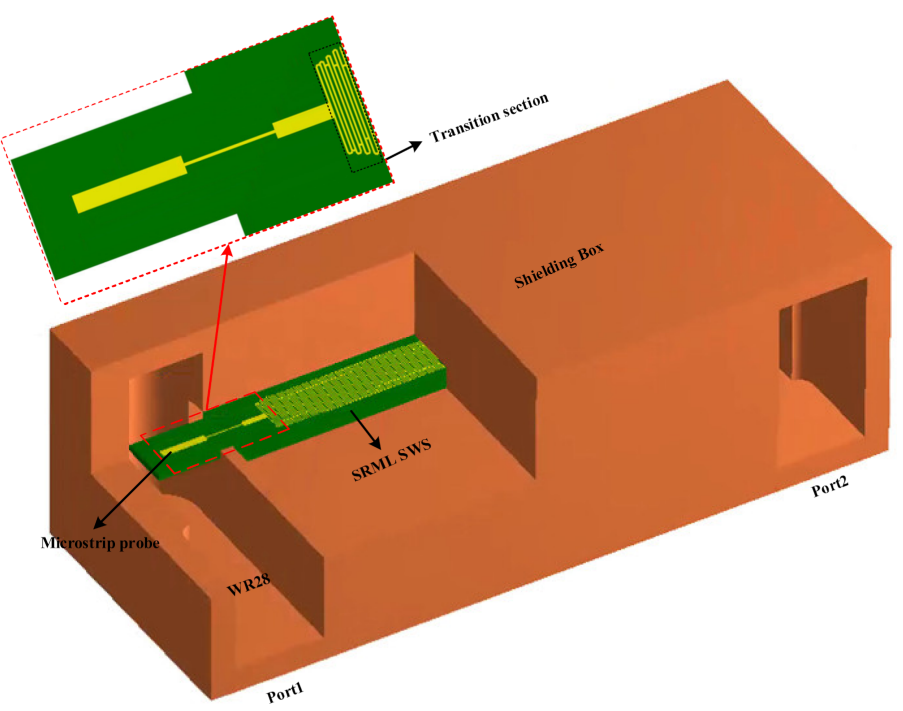

Figure 6. Schematic diagram of SRML SWS transmission model.

Figure 7 shows the reflection loss and the insertion loss of the SRML SWS with input/output waveguides. The reflection coefficient of the SRML SWS is less than $-15 \mathrm{~dB}$ in the frequency range of $26 \mathrm{GHz}$ to $40 \mathrm{GHz}$, and the insertion loss is around $12.5 \mathrm{~dB}$ at the center frequency of $32.5 \mathrm{GHz}$. The simulation results suggest that the designed SRML SWS has good transmission characteristics.

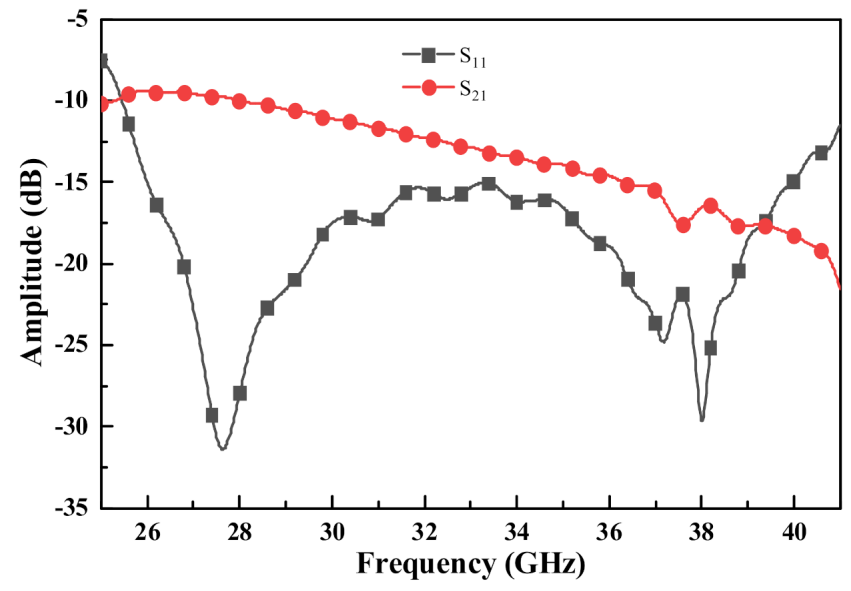

Figure 7. S-parameters of SRML SWS with input/output waveguide.

\section{PIC Simulation of the SRML TWT}

To reduce the simulation time, a model of the SRML SWS without input/output waveguide was established in CST Particle studio, as shown in Figure 8. The model consisted of 250 periods of the SRML SWS, whose length was around $32 \mathrm{~mm}$. As analyzed 
in Section 2, since the adjacent rings of the SRML SWS were staggered placed, the metal line of the SRML SWS had a wider transverse width. So, a wider sheet electron beam could be used to feed DC energy for the beam-wave interaction process. In this simulation, the cross section of the sheet electron beam was $1.9 \mathrm{~mm} \times 0.1 \mathrm{~mm}$, and the beam current was $0.38 \mathrm{~A}$, whose corresponding current density was $200 \mathrm{~A} / \mathrm{cm}^{2}$. The beam voltage was $9.7 \mathrm{kV}$, and the focusing magnetic field was a uniform magnetic field, whose amplitude was 0.8 Tesla.

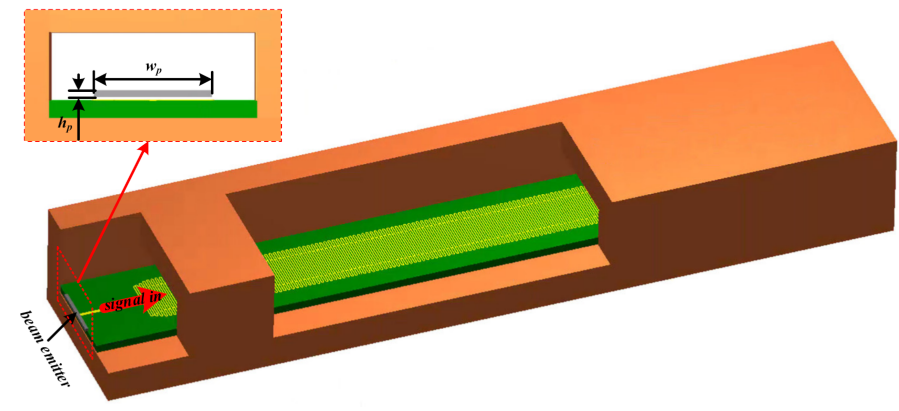

Figure 8. Schematic diagram of SRML TWT model for PIC simulation.

Figure 9 shows the output signal in the time domain at $32.5 \mathrm{GHz}$, and the input power is $1 \mathrm{~W}$. After around $1.2 \mathrm{~ns}$, the output power becomes stable with an amplitude of $25.4 \mathrm{~V}$; the corresponding power and gain are $322.58 \mathrm{~W}$ and $25.09 \mathrm{~dB}$, respectively. Additionally, from Figure 9, the output signal stayed stable in the simulation time of $10 \mathrm{~ns}$, which means that no oscillation occurred.

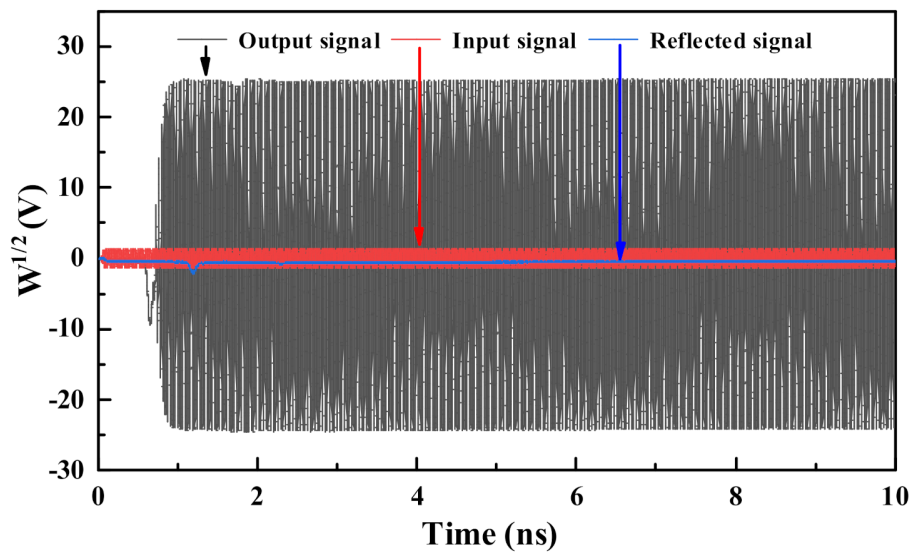

Figure 9. Output signals of the SRML TWT in time domain.

The electron beam trajectories and the phase space diagram after beam-wave interaction has been shown in Figure 10. It shows that the electron beam was well modulated, and there was an obvious transcendence phenomenon at the end of the TWT, indicating that the wave received plenty of energy from the electron beam. Figure 10 also shows that the electron beam smoothly passed through the entire SWS without hitting the dielectric substrate under the constraint of the magnetic field.

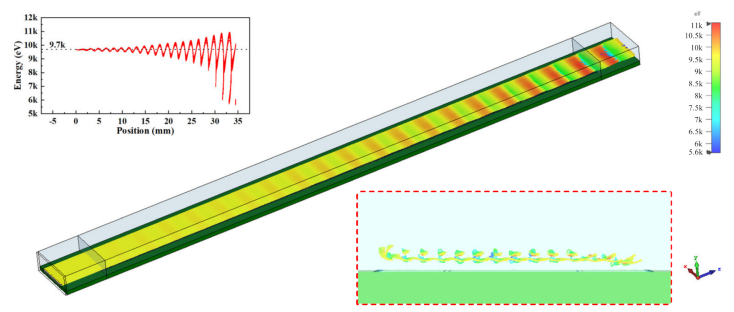

Figure 10. Electron beam bunching and phase space diagram. 
Figure 11 shows the output power varied with frequency. The maximum output power was around $322.58 \mathrm{~W}$ with an electronic efficiency of $8.74 \%$ at $32.5 \mathrm{GHz}$. By slightly decreasing the working voltage, the SRML TWT could have an amplified output power of $26 \mathrm{GHz}$ to $39 \mathrm{GHz}$; the output power was over $100 \mathrm{~W}$ in the frequency range of $27 \mathrm{GHz}$ to $38 \mathrm{GHz}$ and $200 \mathrm{~W}$ in the frequency range of $29 \mathrm{GHz}$ to $37 \mathrm{GHz}$, which means the SRML TWT was a broadband TWT.

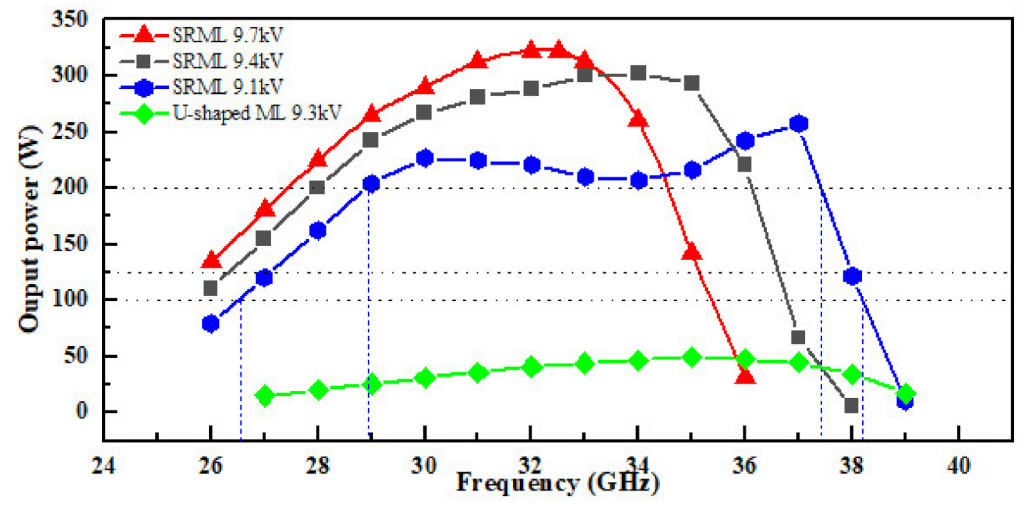

Figure 11. Spectrogram of output signal and reflected signal.

What is more, the output power of the U-shaped ML TWT, which had almost the same phase velocity as the SRML SWS at $32.5 \mathrm{GHz}$, was obtained, as shown by the green line in Figure 11. Although the $3 \mathrm{~dB}$ bandwidth of the SRML TWT was slightly narrower than that of the U-shaped ML TWT, the output power of the SRML TWT was far higher than that of the U-shaped ML TWT. The explanation for this is that the SRML SWS had a wider interaction area, which was almost 3.73 times that of the U-shaped ML SWS, so the SRML TWT could be driven by an electron beam with a higher beam current when the current density was the same.

\section{Discussions}

As a kind of structure that has been well studied in recent years, PCB (printed circuit board) [19], UV-LIGA [6,9], and DRIE [6] technologies have been used to obtain ML SWS successfully. This means SRML SWSs can be fabricated conveniently.

Taking UV-LIGA technology as an example, the processing of SRML SWSs is shown in Figure 12. The first step was to coat a layer of photoresist on the dielectric substrate, and then the cured photoresist was shielded with the specific mask and exposed under ultraviolet light, as shown in Figure 12b. Next, the exposed dielectric substrate was baked and developed to obtain a photoresist mold, as shown in Figure 12c. Finally, the dielectric substrate was metalized, and the required SRML SWS was obtained after removing the photoresist mold, as shown in Figure 12e.

For a TWT, the optical electron system was also very important. In this design, the electron beam adopted in the SRML TWT had a large aspect ratio, which was equal to 19. However, since the perveance and the beam current density were around $0.398 \mathrm{uA} / \mathrm{V}^{3 / 2}$ and $200 \mathrm{~A} / \mathrm{cm}^{2}$, respectively, which are not very high, it could be realized through the common sheet beam electron gun. As the length of the slow-wave circuit was around $44 \mathrm{~mm}$, to maintain the electron beam passing through the slow-wave circuit successfully, a uniform magnetic field will be designed; a uniform magnetic field with an amplitude of around 0.8 Tesla is not very hard to achieve. As shown in Figure 13, a uniform magneticfocusing system was designed. The simulation result of the uniform magnetic is presented in Figure 14. The magnitude of the uniform magnetic field was around 0.81 Tesla, the length of the rising edge of the magnetic field was around $6.8 \mathrm{~mm}$, and the length of the uniform magnetic field was more than $44.4 \mathrm{~mm}$. 


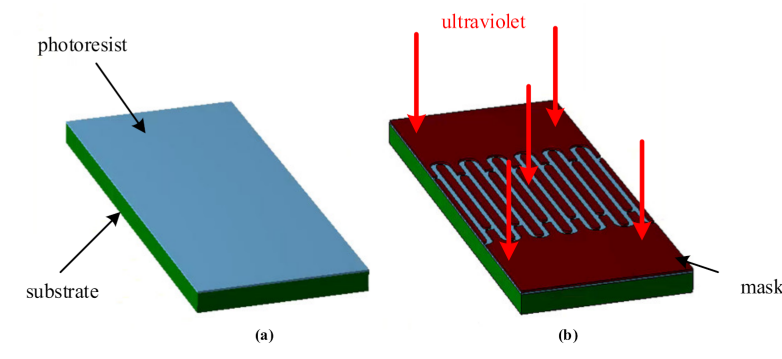

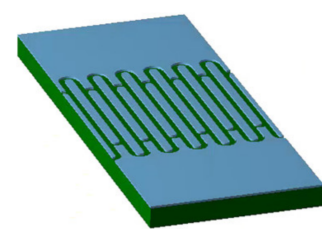

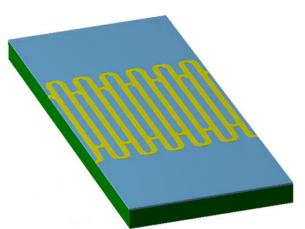

(d)

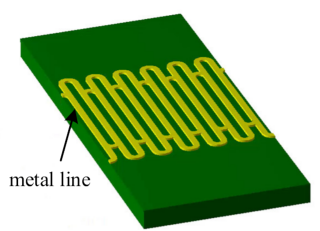

(e)

Figure 12. Diagram of processing SRML SWS by UV-LIGA technology. (a) covering photoresist on dielectric substrate, (b) lithography, (c) photoresist mold after developing, (d) metallization and (e) SRML SWS after removing photoresist.
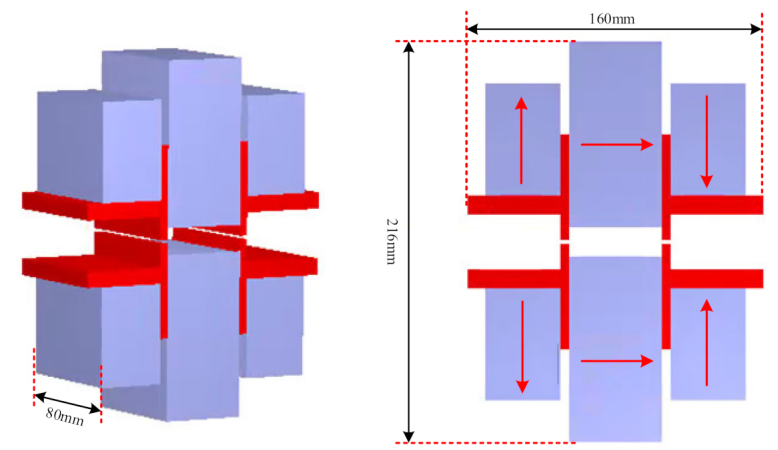

Figure 13. Schematic diagram of uniform magnetic field-focusing system and magnetization direction.

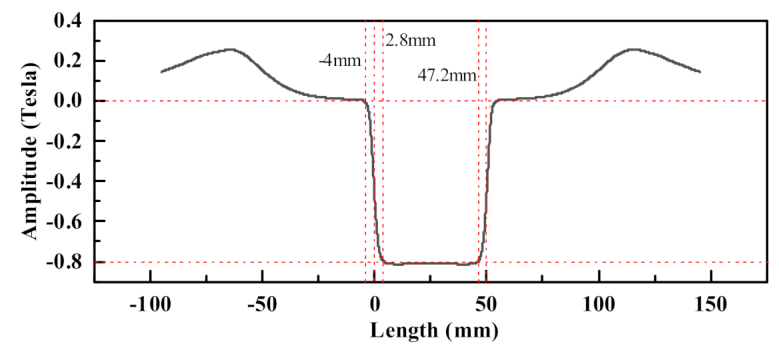

Figure 14. Variation of Z-component of the magnetic field.

\section{Conclusions}

To obtain a higher output power with a microstrip SWS, a SRML SWS has been designed and simulated based on RML SWS. By staggering the adjacent rings of a RML SWS, the transverse of the metal line was enlarged, which means that the SRML SWS had a larger area than the RML SWS for the beam-wave interaction. This feature caused the SRML TWT to have a higher electron beam current than that of the RML TWT when the current density remained the same. So, the output power will be higher. The simulation results of the interaction impedance show that the SRML SWS had a larger value in a wider area, which also indicates that a SRML can have a higher output power. The particle-in-cell simulation results show the designed SRML TWT had a maximum output power of $322.5 \mathrm{~W}$ at $38 \mathrm{GHz}$ with an electronic efficiency of $8.74 \%$, and the $3 \mathrm{~dB}$ bandwidth was over $7 \mathrm{GHz}$. 
Author Contributions: Conceptualization, R.Y., J.X., and P.Y.; methodology, R.Y., G.G., and D.L.; validation, H.Y., H.W., and J.L.; writing—original draft preparation, J.Z. and D.J.; writing-review and editing, J.C., W.W., and L.Y.; supervision, Y.W.; project administration, G.Z., J.X., and L.Y. All authors have read and agreed to the published version of the manuscript.

Funding: This work was supported in part by the Basic Science Center Program of National Natural Science Foundation of China (NSFC) (Grant No. 61988102) and National Natural Science Foundation of China (NSFC) (Grant No. 61771117).

Institutional Review Board Statement: Not applicable.

Informed Consent Statement: Not applicable.

Data Availability Statement: The data presented in this study are available on request from the corresponding author.

Conflicts of Interest: The authors declare no conflict of interest.

\section{References}

1. Qiu, J.; Levush, B.; Pasour, J.; Katz, A.; Armstrong, C.; Whaley, D.; Tucek, J.; Kreischer, K.; Gallagher, D. Vacuum tube amplifiers. IEEE Microw. Mag. 2009, 10, 38-51. [CrossRef]

2. Ghosh, T.K.; Challis, A.J.; Jacob, A.; Bowler, D.; Carter, R.G. Improvements in Performance of Broadband Helix Traveling-Wave Tubes. IEEE Trans. Electron Devices 2008, 55, 668-673. [CrossRef]

3. Legarra, J.; Cusick, J.; Begum, R.; Kolda, P.; Cascone, M. A 500-W Coupled-Cavity TWT for Ka-Band Communication. IEEE Trans. Electron Devices 2005, 52, 665-668. [CrossRef]

4. Liu, S. Folded waveguide circuit for broadband MM wave TWTs. Int. J. Infrared Millim. Waves 1995, 16, 809-815. [CrossRef]

5. Zhang, D.G.; Yung, E.K.N.; Ding, H.Y. Dispersion Characteristics of a Novel Shielded Periodic Meander Line. Microw. Opt. Technol. Lett. 1996, 12, 1-5. [CrossRef]

6. $\quad$ Sengele, S.; Jiang, H.; Booske, J.H.; Kory, C.L.; Van Der Weide, D.W.; Ives, R.L. Microfabrication and Characterization of a Selectively Metallized W-Band Meander-Line TWT Circuit. IEEE Trans. Electron Devices 2009, 56, 730-737. [CrossRef]

7. Sumathy, M.; Augustin, D.; Datta, S.K.; Christie, L.; Kumar, L. Design and RF Characterization of W-band Meander-Line and Folded-Waveguide Slow-Wave Structures for TWTs. IEEE Trans. Electron Devices 2013, 60, 1769-1775. [CrossRef]

8. Socuellamos, J.M.; Dionisio, R.; Letizia, R.; Paoloni, C. Experimental Validation of Phase Velocity and Interaction Impedance of Meander-Line Slow-Wave Structures for Space Traveling-Wave Tubes. IEEE Trans. Microw. Theory Tech. 2021, 69, $2148-2154$. [CrossRef]

9. Ryskin, N.M.; Rozhnev, A.G.; Starodubov, A.V.; Serdobintsev, A.A.; Pavlov, A.M.; Benedik, A.I.; Torgashov, R.; Torgashov, G.V.; Sinitsyn, N.I. Planar Microstrip Slow-Wave Structure for Low-Voltage V-Band Traveling-Wave Tube with a Sheet Electron Beam. IEEE Electron Device Lett. 2018, 39, 757-760. [CrossRef]

10. Chua, C.; Aditya, S. A 3-DU-Shaped Meander-Line Slow-Wave Structure for Traveling-Wave-Tube Applications. IEEE Trans. Electron Devices 2013, 60, 1251-1256. [CrossRef]

11. Bai, N.; Shen, M.; Sun, X. Investigation of Microstrip Meander-Line Traveling-Wave Tube Using EBG Ground Plane. IEEE Trans. Electron Devices 2015, 62, 1622-1627. [CrossRef]

12. Wang, S.; Gong, Y.; Wang, Z.; Wei, Y.; Duan, Z.; Feng, J. Study of the Symmetrical Microstrip Angular Log-Periodic Meander-Line Traveling-Wave Tube. IEEE Trans. Plasma Sci. 2016, 44, 1787-1793. [CrossRef]

13. Shen, F.; Wei, Y.; Yin, H.; Gong, Y.; Xu, X.; Wang, S.; Wang, W.; Feng, J. A Novel V-Shaped Microstrip Meander-Line Slow-Wave Structure for W-band MMPM. IEEE Trans. Plasma Sci. 2011, 40, 463-469. [CrossRef]

14. Shen, F.; Wei, Y.; Xu, X.; Liu, Y.; Huang, M.; Tang, T.; Duan, Z.; Gong, Y. Symmetric Double V-Shaped Microstrip Meander-Line Slow-Wave Structure for W-Band Traveling-Wave Tube. IEEE Trans. Electron Devices 2012, 59, 1551-1557. [CrossRef]

15. Liu, L.; Wei, Y.; Shen, F.; Zhao, G.; Yue, L.; Duan, Z.; Wang, W.; Gong, Y.; Li, L.; Feng, J. A Novel Winding Microstrip Meander-Line Slow-Wave Structure for V-Band TWT. IEEE Electron Device Lett. 2013, 34, 1325-1327. [CrossRef]

16. Chong, D.; Yanyu, W.; Qian, L.; Luqi, Z.; Guo, G.; Yubin, G. A dielectric-embedded microstrip meander line slow-wave structure for miniaturized traveling wave tube. J. Electromagn. Waves Appl. 2017, 31, 1938-1946. [CrossRef]

17. Ding, C.; Wei, Y.; Zhang, L.; Guo, G.; Wang, Y.; Zhang, M.; Lu, Z.; Gong, Y.; Wang, W.; Li, D.; et al. Beam-wave interaction study on a novel Ka-band ring-shaped microstrip meander-line slow wave structure. In Proceedings of the 2014 39th International Conference on Infrared, Millimeter, and Terahertz waves (IRMMW-THz), Tucson, AZ, USA, 14-19 September 2014; pp. 1-2. [CrossRef]

18. Ulisse, G.; Krozer, V. Investigation of a planar metamaterial slow wave structure for traveling wave tube applications. In Proceedings of the 2017 Eighteenth International Vacuum Electronics Conference (IVEC), London, UK, 24-26 April 2017; pp. 1-2. [CrossRef]

19. Guo, G.; Yan, Z.; Sun, Z.; Liu, J.; Yang, R.; Gong, Y.; Wei, Y. Broadband and Integratable $2 \times 2$ TWT Amplifier Unit for Millimeter Wave Phased Array Radar. Electronics 2021, 10, 2808. [CrossRef] 